\title{
Gigabit Ethernet with Wireless Extension: OPNET Modelling and Performance Study
}

\author{
Nurul I Sarkar \\ IT and Software \\ Engineering \\ Auckland university of \\ Technology \\ Auckland, New Zealand \\ nurul.sarkar@aut.ac.nz
}

\author{
Sonia Gul \\ IT and Software \\ Engineering \\ Auckland university of \\ Technology \\ Auckland, New Zealand \\ sonia.gul@aut.ac.nz
}

\author{
Bowen Anderton \\ IT and Software \\ Engineering \\ Auckland university of \\ Technology \\ Auckland, New Zealand \\ ddq2845@aut.ac.nz
}

\begin{abstract}
Gigabit Ethernet (GbE) backbone network with wireless extension is gaining much popularity in campus, small businesses, and corporate network environments worldwide. A good understanding on the impact of wireless extension to a wired backbone network is required for proper design and deployment of such systems. In this paper we investigate the effect of wireless extension (i.e. increasing wireless nodes) on the performance of a GbE backbone network by extensive simulation. We develop a simulation model (using OPNET simulation tool) to study the system performance with and without wireless extension under FTP, VoIP and Video Conferencing traffics for various network scenarios. Results show that FTP download response time and Video packet delays increased about $61 \%$ and $94 \%$, respectively as a result of a wireless extension to the GbE backbone network. The findings reported in this paper provide some insights into the design and deployment of GbE-Wireless networks that may help network planners and engineers to contribute further towards developing next generation wireless networks.
\end{abstract}

Keywords-Gigabit Ethernet, Wireless Extension, OPNET Modelling, Simulation

\section{INTRODUCTION}

Gigabit Ethernet (GbE) has been used as a viable solution for high-speed backbone networking technology especially for wired networks. Many organizations are providing wireless extension to the existing backbone networks to support their employees. However, protocols used in GbE network may not perform well with wireless extension. This paper, therefore, study the impact of increasing wireless nodes on the performance of a $\mathrm{GbE}$ backbone network under both real-time (e.g. Voice and Video) and non-real time (e.g. FTP) traffic loads. Riverbed (OPNET) Modeler (version 17.5) [1] is used for simulation and modelling purposes. Network researchers and engineers use simulation framework extensively to emulate and to validate new network solutions [2-4]. OPNET Modeler was selected because of its availability and simulation credibility.

The idea of integrating IEEE 802.11 (wireless local networks) with IEEE 802.3 (wired LAN) has given a new paradigm to research society. This integration is necessary to allow wireless devices to access the existing network resources. Many studies have been conducted with the concept of integrated networks [5-12]. Most of these studies highlight the advantages especially from the ease of access and mobility viewpoints [13-14]. However, there are very few which also emphasis on the network performance degradation occurs in these integrated networks [15-18].

This paper exploits the issues occur when a wired network is being extended to incorporate wireless devices as part of it. For this we have develop a simulation model for a GbE backbone network with wireless extension. IEEE 802.11a (54 Mbps) wireless cards and access points (APs) are used in modelling.

We have organized the paper in multiple sections for better readability and understanding of our work. Section II provides a background and reviews previous research by highlighting the pros and cons of extending the wired networks with wireless. Simulation and network modeling details are provided in Section III which is followed by results and discussions in Section IV. In Section V we conclude our research work.

\section{BACKGROUND AND RELATED WORK}

With the introduction of wireless extension to the wired networks i.e., devices with wireless transceivers can connect to the wired network if desired by users [9]; allows users to enjoy mobility, wire-free deployment and quick access to network resources if needed. These and many more features are making wireless extensions of wired network very popular. These wireless networks as extension to a wired backbone network going to be around in the future as more and more devices being released with wireless support [5, 20]. However, a wireless network suffers problems related to limited bandwidth than a wired network which is why a wired backbone network is preferred over a wireless backbone $[1,12]$.

The performance of GbE with wireless extension has not been fully explored yet as we have very limited literature on this. However, the performance of Asynchronous Transfer Mode (ATM) backbone network with and without wireless extension are reported in many networking literature. For instance, Sarkar 
et al. [17] have explored the performance of ATM by considering both real (e.g. Voice and Video) and non-real time (e.g. Email and FTP) traffics. Nisar et al. [18] have studied the modelling and performance of integrated ATM and GbE backbone network under voice and video traffic conditions. Both voice and video traffics have more restrictive quality of service (QoS) requirements on end-to-end packet delays than FTP traffic.

In this paper we explore the impact of wireless extension on a GbE backbone network. The simulation details along with the network modeling is discussed next.

\section{NETWORK MODELING AND SIMULATION}

To establish model validation we first simulate a $\mathrm{GbE}$ backbone network (without a wireless extension) and then introduce wireless extension for comparison purposes. The network modelling is discussed next.

\section{A. Modeling the Network}

Fig.1 shows the top level view of network model that we develop to study the performance of GbE backbone with wireless extension. We consider a star topology with four different subnets located in Northeast (NE), Northwest (NW), Southeast (SE), and Southwest (SW) connected through two $\mathrm{GbE}$ switches. We configure the network so that NW office (subnet) can send traffic to the SE office and NE office sends traffic to the SW office.

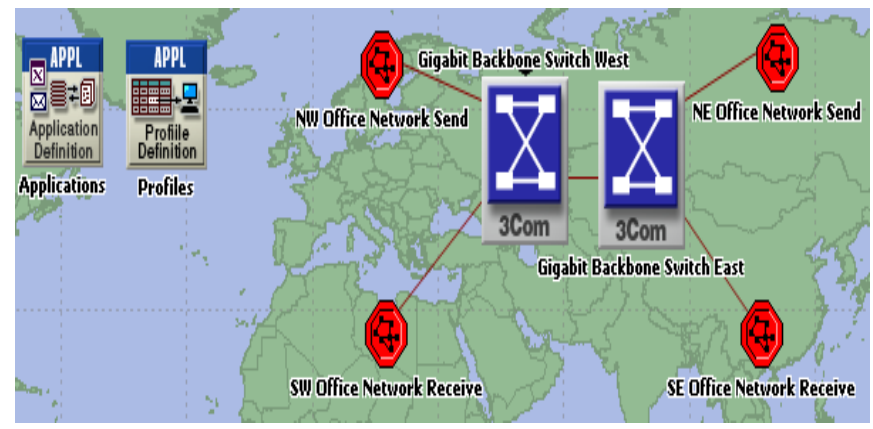

Fig. 1. High level view of Gigabit Ethernet backbone network model with four subnets (NW office; NE Office, SW Office, SE Office)

TABLE I. PARAMETERS USED IN THE SIMULATION

\begin{tabular}{|l|l|}
\hline Parameter & Value \\
\hline wireless cards and APs & IEEE 802.11a (54Mbps) \\
\hline AP Transmit power & $32 \mathrm{~mW}$ \\
\hline Application/Traffic & FTP, VoIP, Video-conferencing \\
\hline Total number of clients & 32 (16 wired and 16 wireless) \\
\hline FTP & high load \\
\hline VoIP encoder & PCM quality \\
\hline Video-conferencing & Low resolution \\
\hline Wireless node mobility & 0 \\
\hline Simulation time & 10 minutes \\
\hline
\end{tabular}

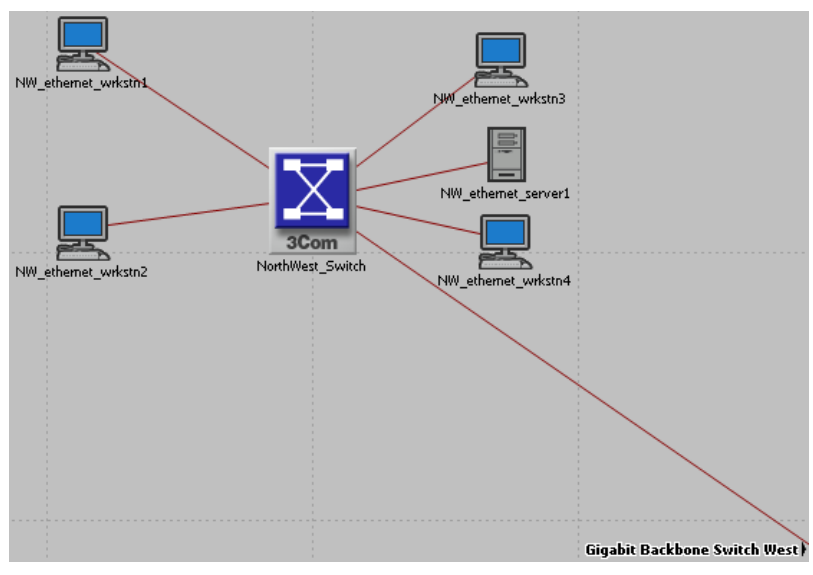

Fig. 2. Northwest subnet model with four wired nodes and a FTP Server (NW_ethernet_Server1).

'Applications Definitions' is used to configure FTP, VoIP, and Video Conferencing applications to be used as traffic sources. The 'Profiles Definitions' is used to setup user (node) profile link to the respective applications. Table I lists parameters used in the simulation.

Fig. 2 shows a GbE network model for Northwest subnet containing four wired nodes and a FTP Server. The wireless extension to Northwest subnet GbE backbone network is shown in Fig. 3. Four wireless nodes are connected to the backbone network via two wireless APs. The number of wireless nodes is increased in the subnet to study the impact of wireless extension on system performance. Overall, we had a total of 16 wired nodes (four nodes per subnet) linked to four GbE backbone switches. We also had 16 wireless nodes connected to $\mathrm{GbE}$ backbone through two wireless APs.

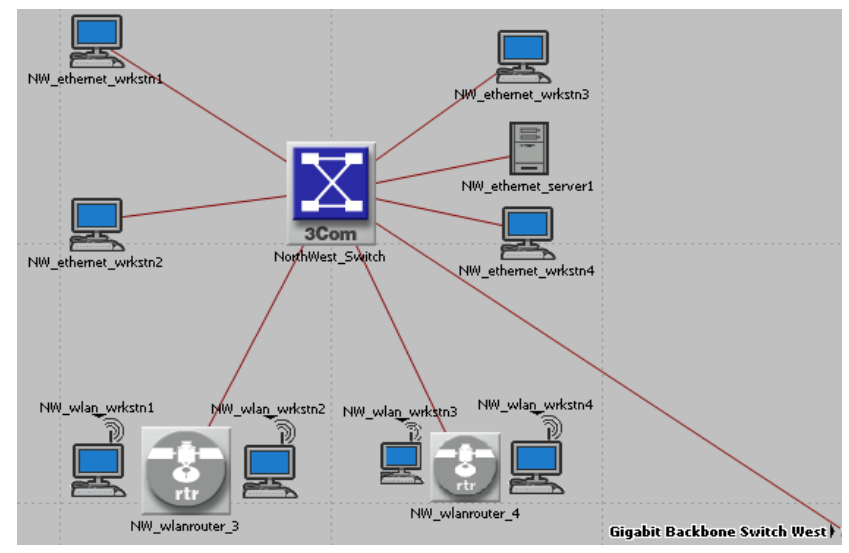

Fig. 3. Northwest subnet model with a wireless extension

\section{B. Configuration of Gigabit-Wireless Extension}

The IEEE 802.11a based wireless network is configured as wireless extension to the $\mathrm{GbE}$ backbone network. The wireless network (infrastructure) radius is set to 100 meters. As we do not consider the mobility of the wireless nodes, the speed is set to zero. We first created a wireless subnet called NW wireless subnet and then repeat the same process for other subnets. The number of nodes in each subnet is increased to study the impact of wireless extension on system performance. 


\section{Simulation Scenarios}

Table II lists the simulation scenarios. In Scenario 1, we consider network-wide FTP clients (users) where all the traffics generated from FTP clients only. In Scenario 2, we consider network-wide VoIP clients where all the traffics generated on the network by VoIP clients only. In Scenario 3, we had network-wide Video Conferencing clients that generate traffics on the network. Unlike Scenarios 1-3, Scenario 4 considers mixed traffics generated from all FTP, VoIP, and Video conferencing clients. The client configuration for FTP, Voice, and Video is shown in Fig. 4.

TABLE II. SIMULATION SCENARIOS

\begin{tabular}{|c|l|}
\hline Scenario & Description \\
\hline 1 & $\begin{array}{l}\text { FTP clients only } \\
\text { All trafics on the network are FTP clients. Total 32 } \\
\text { clients (16 wired and 16 wireless). }\end{array}$ \\
\hline 2 & $\begin{array}{l}\text { VoIP client only } \\
\text { All trafics on the network are VoIP clients. Total 32 } \\
\text { clients (16 wired and 16 wireless). }\end{array}$ \\
\hline 3 & $\begin{array}{l}\text { Video Conferencing clients only } \\
\text { All trafics on the network are Video conferencing } \\
\text { clients. Total 32 clients (16 wired and 16 wireless). }\end{array}$ \\
\hline 4 & $\begin{array}{l}\text { Mixed clients (FTP, Voice and Video) } \\
\text { This is a mixed traffic scenario where trafics are } \\
\text { generated in the network from all clients including FTP, } \\
\text { VoIP and Video; with and without wireless extension. } \\
\text { Total 32 clients (16 wired and 16 wireless). Among the } \\
16 \text { wireless clients, we had 8 FTP, 4 VoIP, and 4 Video } \\
\text { clients. Similar distributions for wired clients. }\end{array}$ \\
\hline
\end{tabular}

\begin{tabular}{|c|c|}
\hline name & NW_ethernet_wrkstn1 \\
\hline \multicolumn{2}{|l|}{ Applications } \\
\hline+ + Application: ACE Tier Confiquration & {$[\ldots]$} \\
\hline - Application: Destination Preferences & {$[\ldots]$} \\
\hline Number of Rows & 3 \\
\hline \multicolumn{2}{|l|}{ - Video } \\
\hline Application & Video \\
\hline Symbolic Name & Video Destination \\
\hline$\bigoplus$ Actual Name & {$[\ldots]$} \\
\hline Number of Rows & 1 \\
\hline$\oplus$ SE_ethernet_wrkstn1 & $\ldots$ \\
\hline \multicolumn{2}{|l|}{$\boxminus$ FTP } \\
\hline Application & FTP \\
\hline Symbolic Name & FTP Server \\
\hline - Actual Name & {$[\ldots]$} \\
\hline Number of Rows & 4 \\
\hline ÐNW_ethernet_server1 & $\ldots$ \\
\hline$\mp$ NE_ethernet_server1 & $\ldots$ \\
\hline † SW_ethernet_server1 & $\ldots$ \\
\hline $\pm S E$ ethernet_server1 & $\ldots$ \\
\hline \multicolumn{2}{|l|}{- Voice } \\
\hline Application & Voice \\
\hline .. Symbolic Name & Voice Destination \\
\hline - Actual Name & {$[\ldots]$} \\
\hline Number of Rows & 1 \\
\hline † SE_ethernet_wrkstn1 & $\ldots$ \\
\hline
\end{tabular}

Fig. 4. FTP, Voice, and Video client configuration

\section{RESULTS AND DISCUSSION}

All simulation results report the steady state behavior of the network and were obtained with a relative statistical error $\leq 1 \%$, at the $99 \%$ confidence level. Each simulation run lasted for 10 minutes simulated time where the first minute was the transient period. The observations collected during the transient period are not included in the final simulation results.

We measure download and upload response times for FTP throughput, packet delays, and jitter for VoIP; and throughput and packet delays for Video conferencing.

\section{A. Results for Network-wide FTP Clients (Scenario 1)}

Fig. 5 shows the download and upload response times for FTP clients with and without wireless extension. We observe that both download (Fig. 5a) and upload (Fig. 5b) response times increase with wireless extension into the $\mathrm{GbE}$ backbone network. For instance, as a result of wireless extension, FTP download and upload response times increased about $13.1 \%$ and $19 \%$, respectively. The main conclusion is that wireless extension has a negative impact on FTP response times. This is due to network congestion caused by increasing wireless nodes in the network.

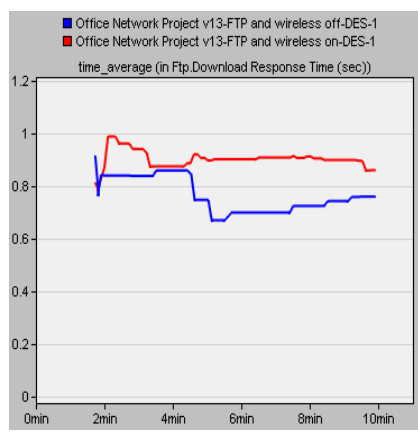

(a) FTP Download (sec)

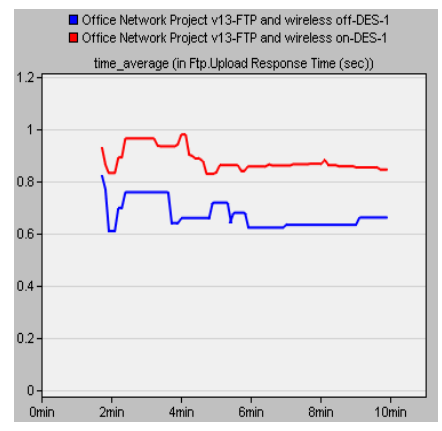

(b) FTP Upload (sec)
Fig. 5. FTP Response times for network-wide FTP clients

\section{B. Results for Network-wide VoIP Clients (Scenario 2)}

Fig. 6 shows VoIP jitter performance for Scenario 2. Jitter is detected if there is a variation in the packet delays received by VoIP nodes in the network. When packets are sent to the receiver, normally they are sent continuously and the packets are spaced evenly apart. When there is overcrowding, congestion and errors in the network the packets are delayed and are not spaced evenly; this causes a lumpy stream or jitter this is called positive jitter. Negative jitter is the same except that once the packets are no longer being delayed jitter returns to as close as zero as possible unless there is more traffic [1]. This can be explained in the graph with the wired backbone network when there is no jitter at all (the blue line is straight as the packets are being sent smoothly) but when a wireless extension is added to the network there is jitter (red line) but the jitter becomes stable and reach steady-state over the simulated time which is good.

Fig. 7 shows VoIP packet delay performance for networkwide VoIP clients. We observe that VoIP packet delay increased about $1 \%$ as a result of wireless extension which is very minimal and we can draw the conclusion that wireless extension to the 
backbone network has insignificant impact on VoIP packet delays.

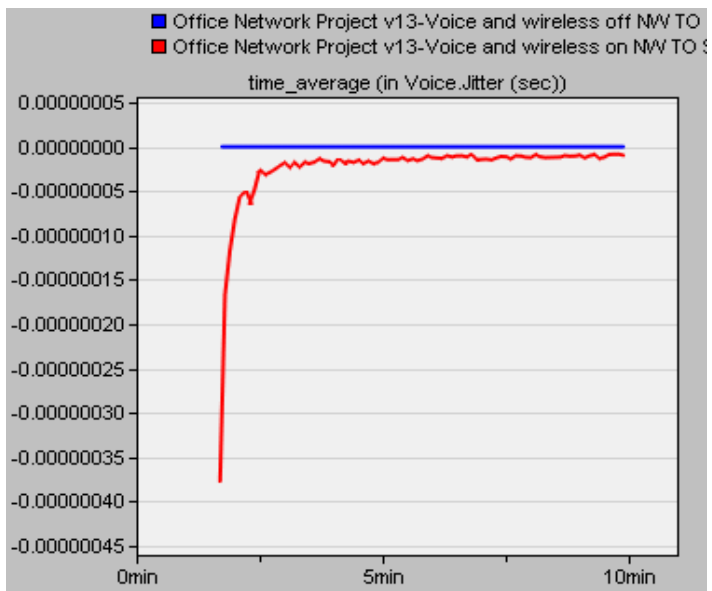

Fig. 6. Voice Jitter performance for network-wide VoIP clients

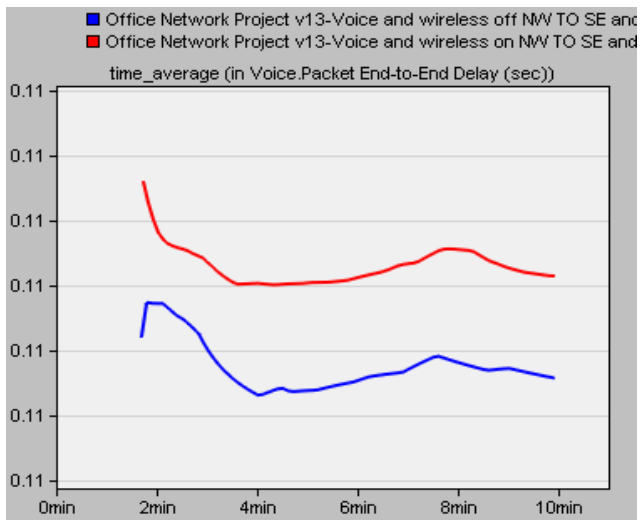

Fig. 7. Voice packet delay performance for network-wide VoIP clients

Fig. 8 shows VoIP throughput performance for GbE backbone network with and without wireless extension. The VoIP throughput (measured in packets/sec) is a successful delivery of packets to the destination nodes [20]. We observe that network-wide VoIP throughput increased about $42 \%$ suggesting that a wireless extension has a positive effect on VoIP throughput. This throughput increase is due to more traffic on the network as a result of increased wireless nodes.

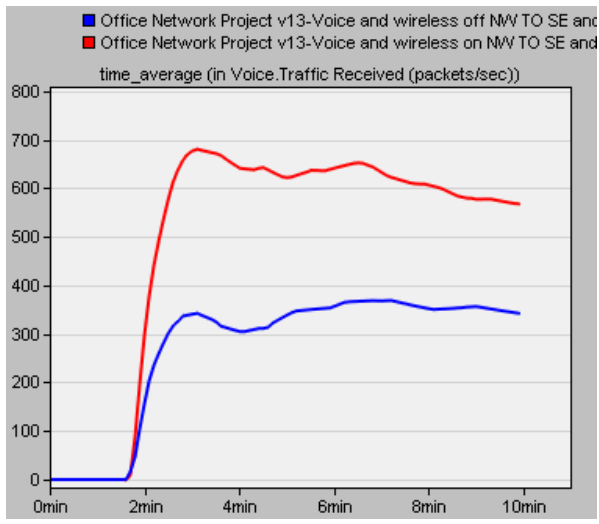

Fig.8. Voice throughput performance for network-wide VoIP clients

\section{Results for Network-wide Video Conferencing Clients (Scenario 3)}

Fig. 9 shows video conferencing packet delay performance for network-wide video traffic. We observe that as a result of a wireless extension to the backbone network, video conferencing packet delays increased about $38 \%$. The main conclusion is that wireless extension has a negative effect on video packet delays.

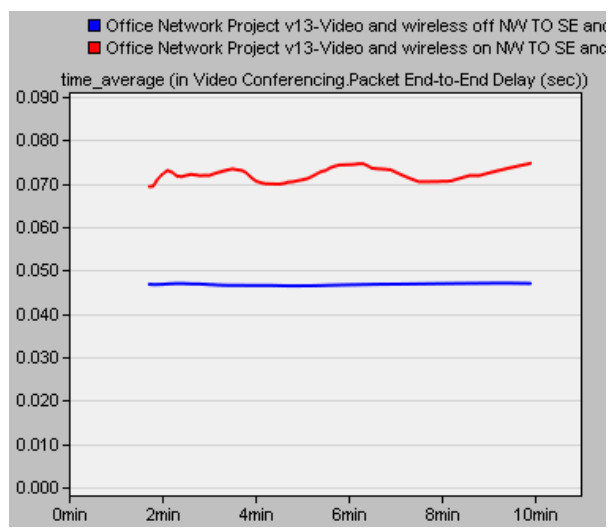

Fig.9. Video delay performance for network-wide Video Conferencing clients

Fig. 10 shows video throughput (measured in packets/sec) performance with and without wireless extension. This throughput is a measure of successful packet delivery to the destination nodes. We observe that video throughput is increased about $56 \%$ which is significant. This throughput increase is as a result of more wireless nodes on the network contributing to more successful packet delivery.

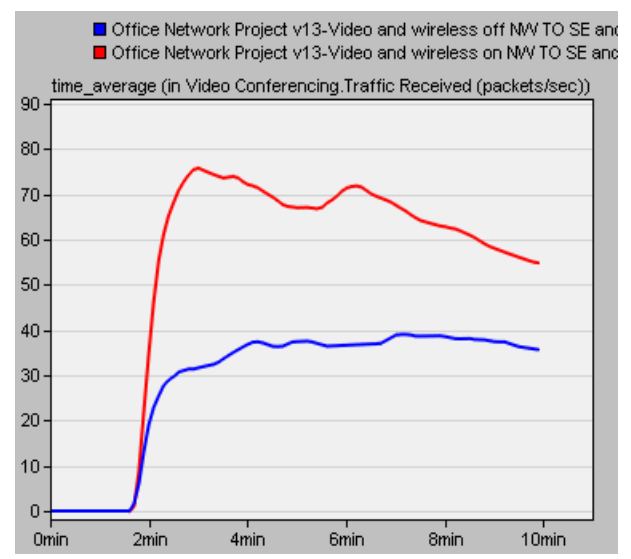

Fig.10. Video throughput performance for network-wide Video Conferencing clients

\section{Results for Mixed Clients (FTP, Voice, and Video)- Scenario 4}

Fig. 11 shows the FTP download response time (Fig. 11a) and upload response time (Fig. 11b) for the mixed clients with and without wireless extension. For instance, as a result of wireless extension, FTP download and upload response times increased about $61 \%$ and $10 \%$, respectively. The main conclusion is that wireless extension has a negative impact on FTP response times. This negative impact is due to network 
traffic congestion caused by increased wireless nodes in the network.

Fig. 12 shows VoIP jitter for network-wide mixed clients. We observe that wireless extension to the backbone network has insignificant effect on VoIP jitter.

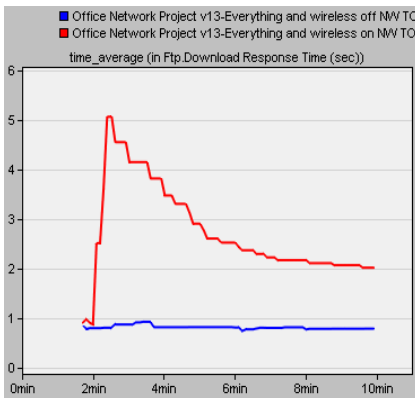

(a) Download response time (sec)

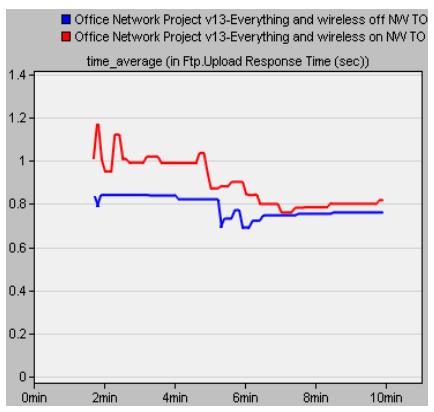

(b) Upload response time $(\mathrm{sec})$
Fig. 11. FTP Response times for mixed clients

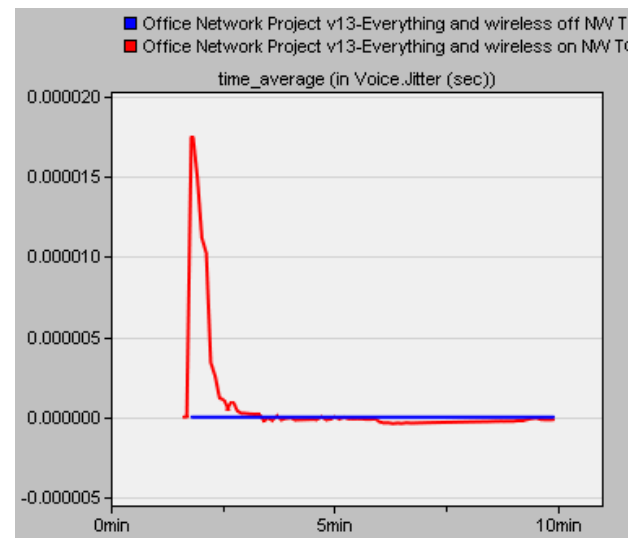

Fig. 12. VoIP Jitter for mixed clients

Fig. 13 shows VoIP throughput performance for networkwide mixed clients. One can observe that VoIP throughput is increased about 56\% due to wireless extension to the backbone network. This is expected because more wireless traffics successfully delivered to the destination nodes contributing to higher throughput.

Fig. 14 shows Video conferencing packet delays for network-wide mixed clients (FTP, Voice, and Video). We observe that video packet delay is increased about $94 \%$ as a result of wireless extension to the backbone network. The main conclusion is that wireless extension has a significant negative impact on video packet delays. This will affect QoS as well as quality of experience (QoE) of video streaming on the network.

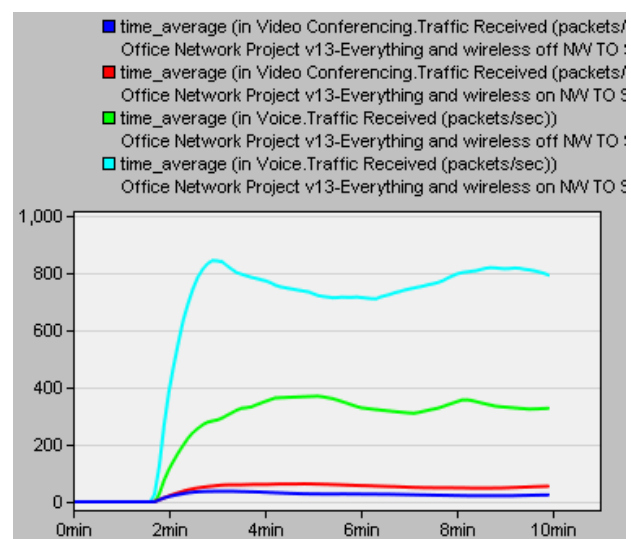

Fig.13. VoIP Throughput performance for mixed clients

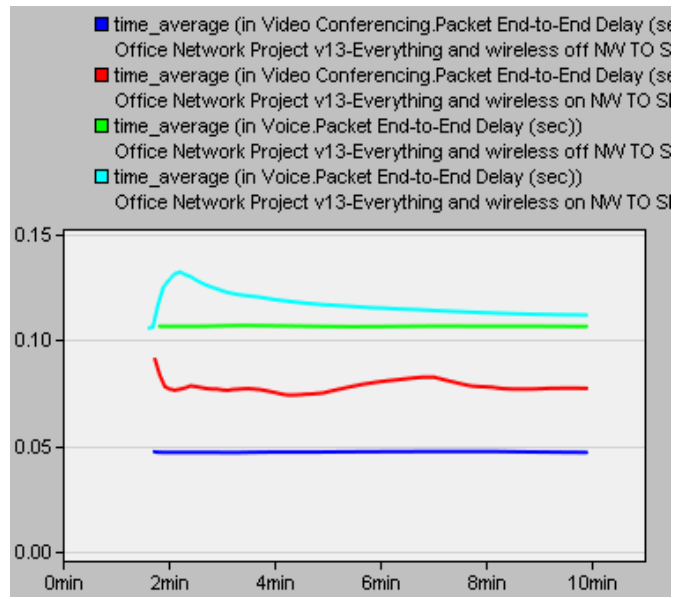

Fig.14. Video conferencing packet delay for mixed clients

TABLE III. SUMMARY OF FINDINGS FOR MIXED CLIENTS SCENARIO (FTP, VOICE, AND VIDEO IN OPEATING)

\begin{tabular}{|c|c|c|c|c|}
\hline \multirow[b]{2}{*}{ Traffic } & \multirow[b]{2}{*}{$\begin{array}{l}\text { Performance } \\
\text { Metrics }\end{array}$} & \multicolumn{2}{|c|}{ Performance } & \multirow{2}{*}{$\begin{array}{l}\text { Performance } \\
\text { degradation } \\
(\%)\end{array}$} \\
\hline & & $\begin{array}{l}\text { With } \\
\text { Wireless }\end{array}$ & $\begin{array}{l}\text { Without } \\
\text { Wireless }\end{array}$ & \\
\hline \multirow{2}{*}{ FTP } & $\begin{array}{l}\text { Download response } \\
\text { time }(\mathrm{sec})\end{array}$ & 2.03 & 0.8 & 60.6 \\
\hline & $\begin{array}{ll}\text { Upload } & \text { response } \\
\text { time }(\mathrm{sec}) & \end{array}$ & 0.845 & 0.76 & 10.1 \\
\hline \multirow[b]{2}{*}{ Voice } & Packet delay (sec) & 0.112 & 0.106 & 5.4 \\
\hline & $\begin{array}{l}\text { Throughput } \\
\text { (packet/sec) }\end{array}$ & 800 & 350 & 56.3 \\
\hline \multirow[b]{2}{*}{ Video } & Packet delay (sec) & 0.78 & 0.047 & 94.0 \\
\hline & $\begin{array}{l}\text { Throughput } \\
\text { (packet/sec) }\end{array}$ & 54.9 & 35 & 36.2 \\
\hline
\end{tabular}

\section{E. Simulation Model Validation}

Although Riverbed OPNET Modeler is one of the credible network simulation tools, it may produce invalid results if the simulation parameters are incorrectly configured. We validate our simulation models in the following ways. First, we checked simulation log files to ensure that there was no errors and the simulation models run smoothly. Second, the function of wired 
backbone network components and their interactions was checked before introducing wireless extension. Third, the network performance with a single user was tested and compared with testbed results. Finally, we compared our results with similar work in the literature to ensure that we are on the right track [16].

\section{CONCLUDING REMARKS}

In this paper we have investigated the impact of wireless extension on the performance of a Gigabit Ethernet (GbE) backbone network. We considered both real-time (e.g. VoIP and Video Conferencing) and non-real time (e.g. FTP) traffics in the investigation. We studied the system performance with and without wireless extension by OPNET-based extensive simulations.

Results obtained have shown that FTP download response times and video conferencing packet delays increased about $61 \%$ and $94 \%$, respectively; indicating significant performance drawbacks as a result of wireless extension to the backbone network. These results are valid for only mixed traffic scenario containing 32 clients of which 16 wireless with 8 FTP, 4 VoIP, and 4 Video Conferencing clients. However, the impact of wireless extension on VoIP packet delays for the mixed traffic scenario is found to be insignificant.

For individual traffic scenarios (Table II Scenarios 1-3) where all 32 nodes are either FTP, VoIP or Video Conferencing clients only. We found that FTP download and upload response times increased about $13 \%$ and $19 \%$, respectively for a wireless extension to the backbone network. The main conclusion is that wireless extension has a negative impact on FTP response times to some extend but not as high as the mixed traffic scenario. For VoIP clients only scenario, the impact of wireless extension on VoIP packet delays is found to be insignificant. Finally, for the case of Video Conferencing clients only, the impact of wireless extension on video packet delays is found to be moderately significant but not as high as the mixed traffic scenario.

An investigation of the impact of multimedia traffic over GbE-Wireless network to access QoS and QoE is suggested as future research.

\section{REFERENCES}

[1] Application and Network Performance with OPNET Monitoring, Troubleshooting, Auditing, and Prediction. OPNET. Retrieved September 03, 2018, from http://www.opnet.com/

[2] Costa, X. P., \& Hartenstein, H. (2002). A simulation study on the performance of Mobile IPv6 in a WLAN-based cellular network. Computer Networks, 40(1), 191-204.

[3] N. I. Sarkar and J. Gutierrez, "Revisiting the Issue of the Credibility of Simulation Studies in Telecommunication Networks: Highlighting the Results of a Comprehensive Survey of IEEE Publications," IEEE Communications Magazine, vol. 52, no. 5, pp. 218-224, 2014.

[4] N. I. Sarkar and S. A. Halim, "A review of simulation of telecommunication networks: simulators, classification, comparison, methodologies, and recommendations," Journal of Selected Areas in Telecommunications (JSAT), vol. 2, pp. 10-17, March 2011.

[5] Zhang, N., Zhang, S., Yang, P., Alhussein, O., Zhuang, W., \& Shen, X. S. (2017). Software defined space-air-ground integrated vehicular networks: Challenges and solutions. IEEE Communications Magazine, 55(7), 101-109.

[6] Pirouzi, S., Aghaei, J., Vahidinasab, V., Niknam, T., \& Khodaei, A. (2018). Robust linear architecture for active/reactive power scheduling of EV integrated smart distribution networks. Electric Power Systems Research, 155, 8-20.

[7] Akyildiz, I. F., \& Wang, X. (2005). A survey on wireless mesh networks. IEEE Communications magazine, 43(9), S23-S30.

[8] Liang, C., \& Yu, F. R. (2015). Wireless network virtualization: A survey, some research issues and challenges. IEEE Communications Surveys \& Tutorials, 17(1), 358-380.

[9] Xiao, Y., Leung, K. K., Pan, Y., \& Du, X. (2005). Architecture, mobility management, and quality of service for integrated $3 \mathrm{G}$ and WLAN networks. Wireless Communications and Mobile Computing, 5(7), 805823.

[10] Chakravorty, R., Vidales, P., Subramanian, K., Pratt, I., \& Crowcroft, J. (2004, March). Performance issues with vertical handovers-experiences from GPRS cellular and WLAN hot-spots integration. Proceedings of the Second IEEE Annual Conference on Pervasive Computing and Communications, (pp. 155-164).

[11] Carmo, M., Jardim, S., Neto, A., Aguiar, R., Corujo, D., \& Rodrigues, J. J. (2018, May). Slicing WiFi WLAN-Sharing Access Infrastructures to Enhance Ultra-Dense 5G Networking. IEEE International Conference on Communications (pp. 1-6).

[12] Amewuda, A. B., Katsriku, F. A., \& Abdulai, J. D. (2018). Implementation and Evaluation of WLAN 802.11 ac for Residential Networks in NS-3. Journal of Computer Networks and Communications, 2018.

[13] Bianchi, G. (2000). Performance analysis of the IEEE 802.11 distributed coordination function. IEEE Journal on selected areas in communications, 18(3), 535-547.

[14] Aust, S., Prasad, R. V., \& Niemegeers, I. G. (2012, June). IEEE 802.11 ah: Advantages in standards and further challenges for sub $1 \mathrm{GHz}$ Wi-Fi. IEEE International Conference on Communications (pp. 6885-6889).

[15] Raniwala, A., \& Chiueh, T. C. (2004, August). Evaluation of a wireless enterprise backbone network architecture. Proceedings of the 12th Annual IEEE Symposium on High Performance Interconnects (pp. 98-104).

[16] Wu, E. K., \& Chen, M. Z. (2004). JTCP: Jitter-based TCP for heterogeneous wireless networks. IEEE Journal on Selected Areas in Communications, 22(4), 757-766.

[17] N. I. Sarkar, K. Nisar, and H. Chieng, "Modelling and Performance Studies of ATM Networks over Email, FTP, Voice \& Video," International Journal of Information Communication Technologies and Human Development (IJICTHD), vol. 5, no. 4, 2013.

[18] K. Nisar, N. I. Sarkar, and Y. Dole, "Performance studies of voice and video conferencing over ATM and Gigabit Ethernet backbone networks," International Journal of Technology Diffusion (IJTD), vol. 3, no. 1, pp. 22-32, 2012.

[19] K. Pawlikowski, H.-D. J. Jeong, and J.-S. R. Lee, "On credibility of simulation studies of telecommunication networks," IEEE Communications Magazine, vol. 40, no. 1, pp. 132-139, 2002.

[20] Mahmood, A., Exel, R., \& Sauter, T. (2014). Delay and jitter characterization for software-based clock synchronization over WLAN using PTP. IEEE Transactions on industrial informatics, 10(2), 11981206 